\title{
Comunicación

\section{EI teléfono celular y las aproximaciones para su estudio}

\author{
ANA LUZ RUELAS 1
}

En este artículo se abordan los principales antecedentes del estudio del teléfono fijo, que nos dan un marco apropiado para introducirnos al estudio del teléfono celular, comparando los inicios de la adopción de ambas tecnologías, así como sus efectos sociales. Se discuten también algunos enfoques sugeridos por estudiosos de las comunicaciones pues son un marco para analizar este dispositivo de la comunicación. Otorgamos especial atención a las iniciales visiones distópicas que provocó su proliferación, como contraste a la euforia, o visiones utópicas que comúnmente proviene de la industria y la publicidad.

PALABRAS CLAVE: teléfono fijo, teléfono celular, efectos sociales, visiones distópicas, medio subversivo.
This article presents the major background to the study of fixed telephones, which gives us an appropriate framework for introducing us to study the cell phone and make some comparisons about the early adoption of both technologies, and its social effects. We discuss also some focuses suggested by scholars of communications and serving as a framework for analyzing this communication device. We offer special attention to the initial dystopian reactions stressed by some scholars, as a form of contrasting the euphoria of the industry and its publicity.

KEY WORDS: fixed telephones, cell phones, social effects, dystopic visions, subersive media.

1 Universidad Autónoma de Sinaloa, México.

Correo electrónico: aruelas@uas.uasnet.mx 
La omnipresencia del teléfono celular en diversas esferas de la vida social hace imperativo su abordaje desde diferentes perspectivas de análisis. Ningún artefacto de comunicación se había diseminado con tanta rapidez ni había inducido en tan poco tiempo efectos múltiples en las relaciones humanas, el comportamiento público, la modificación de los conceptos de espacio público y privado, así como reacciones ambivalentes en los usuarios. Cabrera (2006) lo cataloga como un aparato que se ha "naturalizado" en la sociedad contemporánea "por la familiaridad con que una generación completa está convencida de que siempre hubo móviles" (p. 96). Es un artefacto que brinda enorme visibilidad, impone modas, es fuente de identidad para los jóvenes, es adictivo, se porta como parte de la vestimenta y sustituye en tiempos record a otras tecnologías como la cámara fotográfica y grabadora; también es indispensable como reloj despertador, calculadora, agenda de actividades, etc. Por ello, para estudiarlo, ameritamos "articular los recursos... de diferentes ramas (científicas) y enfoques... para producir conocimiento pertinente y consistente y que responda a las necesidades sociales" (Pálau, 2008, p. 5).

Aun cuando se pudiera interpretar que algunas de nuestras reflexiones adoptan forma de determinismo tecnológico, queremos dejar en claro que para nosotros las tecnologías de información y comunicación se adoptan y diseñan en un contexto social, cultural e histórico específico. Por ejemplo, si bien el celular en México ha sido abrazado con gran intensidad por los jóvenes, la frecuencia de su uso para enviar mensajes o voz depende en mucho de las tarifas impuestas por las compañías celulares. Así mismo, las limitantes de pobreza patrimonial de los jóvenes y el abuso de las empresas ha orillado a éstas a buscar esquemas de prepago, primero a través de tarjetas y luego de las recargas en tiendas de autoservicio por sumas de dinero mínimas, lo que facilita la disposición del teléfono celular (Ruelas, 2010).

\section{EL TELÉFONO FIJO Y SUS ANTECEDENTES PARA ESTUDIAR EL TELÉFONO CELULAR}

El teléfono fijo ha pasado a la historia como una tecnología relegada de los análisis sociales y hoy se le menciona tangencialmente para diferenciarlo del teléfono celular, que ha llamado profusamente la aten- 
ción de diferentes disciplinas sociales y humanísticas. Conocer aunque sea someramente la suerte que corrió el estudio del teléfono fijo o "de casa", es un antecedente útil para adentrarnos al análisis de los primeros efectos sociales de este dispositivo de comunicación.

Las razones de tal orfandad provienen tanto de las características del teléfono y su apropiación en los hogares, como del surgimiento reciente de la comunicación como área de estudio y las diferencias entre la comunicación masiva y la comunicación interpersonal, además de otras consideraciones.

Entre las explicaciones del déficit de estudios del teléfono fijo están, en primer lugar, las del sociólogo Ithiel de Sola Pool (1977), quien argumentó que cuando el campo de la comunicación emergió durante las décadas de los años cuarenta y cincuenta, el estatus que tenía el teléfono no le favoreció para despertar el interés analítico pues en ese entonces se concibió como un medio "viejo", ya que se había inventado en el último cuarto del siglo XIX.2 Por su parte, para Rogers (1986), la naturaleza interactiva del teléfono no congeniaba con los modelos unidireccionales de uno a muchos, prevaleciente en los años de formación del área de estudios de la comunicación.

Williams y Rice (1993) señalaron que precisamente el teléfono era el menos estudiado de los instrumentos de comunicación por las ciencias sociales, entre los que tenían más de medio siglo como el televisor (décadas 1930 y 1940) e incluso entre los más recientes como la videocasetera (video cassette recorder), ${ }^{3}$ pues, comúnmente, cuando se estudian las conversaciones mediadas por el teléfono no se considera su especificidad ni las propiedades de la interacción que permite. Esa suerte le viene por ser un objeto inserto en un "mundo ya organizado" que oculta el proceso durante el cual la tecnología se hizo parte de la rutina.

2 Aunque es mundialmente conocido que Alexander G. Bell inventó el teléfono en 1876, en 1992 el Congreso de Estados Unidos reconoció la contribución desde 1854 del italiano Antonio Meuci a este mismo invento.

3 El primer formato fue el Betamax, introducido por Sony en 1976 para grabar programación de televisión. Este formato fue desplazado por el de VHS en 1977, aunque ambos se mantuvieron a la vez en el mercado por un corto periodo. 
Para diferenciarlo de los tradicionales medios masivos de comunicación como la radio y la televisión, al teléfono se le cataloga como un instrumento eminentemente de la vida cotidiana, como el conducto de los detalles mundanos, como conversar con los allegados, compañeros, amigos y manejar los asuntos que van surgiendo. A diferencia de éste, los medios masivos nos dan la sensación de lo inusual, muestran fotografías vívidas y dramáticas de guerras, terremotos y acontecimientos conmocionantes y ocupan el centro del ámbito cultural (Dimmik, Skland \& Paterson, 1994, p. 645).

Se le cataloga, asimismo, como una tecnología naturalizada, o el más transparente de los medios electrónicos, pues al "hablar con alguien por teléfono, es tan natural que casi olvidamos la intermediación del medio" (Meyrowitz citado en Cooper, 2002, p.19). Aunque se ha mantenido irrelevante para las ciencias sociales y ahora se le menciona de manera tangencial, obligadamente para diferenciarlo del móvil que sí ha suscitado en muy poco tiempo amplias discusiones entre comunicólogos, sociólogos y otros científicos.

Otra razón válida para explicar la escasez de atención analítica del teléfono fijo, en comparación con otros canales de comunicación como la televisión y la radio, obedece en mucho, como sostiene Cooper (2002), a que se convirtió en un medio mundano, un mueble más de la casa, o por ser un simple medio que deja correr el habla.

El olvido del teléfono fijo se ubica en una discusión sobre la división tradicional de los campos de la comunicación, concretamente entre la comunicación masiva y comunicación interpersonal, cuyo punto de confluencia a final de cuentas es que ambas lo relegaron como objeto de estudio. ${ }^{4}$ No obstante que en ambos campos se reconoce la

4 En una intensa discusión por correo electrónico entre algunos miembros del grupo de Investigadores de Internet en julio de 2006 (Association of Internet Researchers), se puso en cuestionamiento, para la actualidad incluso, el uso del término face to face (cara a cara). Se admitió que la expresión comunicación mediada ha adquirido diferentes dimensiones, en virtud de la digitalización de las comunicaciones en sus diferentes expresiones. Si hablamos de que hay una mediación por computadora, que puede ser también el caso del teléfono móvil, pues tenemos que admitir que el término 
importancia de las llamadas telefónicas como forma de comunicación, esto fue soslayado, pues por un lado, al no darse la interacción cara a cara en las conversaciones telefónicas, no se consideraron dentro de la esfera de la comunicación interpersonal, pero tampoco se les dio el tratamiento como comunicados para una audiencia heterogénea, anónima y relativamente grande (Sarch, 1993, pp. 128-129) para ser tomada como comunicación masiva, es decir, que no ejemplifica el paradigma característico de las comunicaciones masivas, que reconoce el enlace de "uno a muchos".

Las profesoras Kathleen Reardon y Everett Rogers (1988) centraron su atención en las posibilidades de retroalimentación de las comunicaciones masiva e interpersonal. Señalaron que hasta mediados de la década de los años setenta las definiciones de comunicación interpersonal se limitaron a las interacciones cara a cara, entre dos o pocas personas, quienes tenían la oportunidad de retroalimentarse. Los medios masivos fueron definidos durante décadas como "transmisores" de mensajes (prensa, radio y televisión) que permitían a uno o pocos individuos llegar a una audiencia amplia y la retroalimentación era muy limitada. Con estos parámetros, obviamente las conversaciones mediadas por el teléfono fijo no tenían cabida.

Para Reardon y Rogers (1988, pp. 285-286) las comunicaciones interpersonales y las comunicaciones masivas se diferenciaron por tres elementos: a) el tipo de canal, b) el número potencial de receptores de los mensajes y c) la posibilidad de la retroalimentación. Todavía en la década de los años ochenta muchos académicos se constreñían por esas definiciones que no ayudaron a concebir a la comunicación como un proceso complejo, que va más allá de la simple relación de causa-efecto y que amerita tomar en cuenta que las consecuencias de la exposición a los medios son variadas y complejas, que la gente usa la información para construir significados, que hay influencias mutuas, y que la información puede convertirse en acción. Reardon y Rogers sostienen

comunicación mediada es un término útil, o más precisamente el de CMC (computer mediated communication), como comentaba Lauren M. Squires, lingüista y especialista en discurso mediado por cómputo de la Universidad de Michigan en Ann Harbor. 
también que las distinciones entre las comunicaciones interpersonales y masivas se han sobreestimado y han ido en detrimento del progreso de la teoría e investigación (p. 293). Muestran a través de un análisis de citas cruzadas en revistas de comunicación en 1981, que por ejemplo, quienes estudian a los medios masivos citan muy esporádicamente artículos de las revistas dedicadas a las comunicaciones interpersonales, y estos últimos hacen algo similar. También concluyen que existe una falsa dicotomía entre ellas, pues las nuevas tecnologías de comunicación son de naturaleza interactiva y no se pueden categorizar como canales de comunicación interpersonales o masivos, y que la interactividad que propician, incluido hoy el celular, las hace más interpersonales, a la vez que pueden llegar a muchos más individuos (p. 297). Más recientemente, García (2008) coincide en que las ciencias de la comunicación en particular "quedan definidas por su objeto de estudio multidimensional... por los niveles interpersonal, grupal, organizacional, mediático y cultural (opinión pública)” (p. 5).

Para 2005, ante la ola de diseminación celular y con las diferentes aplicaciones que se les incorporan como mensajes de voz, envío de imágenes, fotografías, música y correo electrónico, el filósofo búlgaro Kristof Nyiri (2005) lo asumió como "un instrumento de la comunicación mediada único, que no media sólo entre personas, sino entre ellas y las instituciones y con los objetos inanimados". Es hoy el medio dominante, en el sentido de que "conjuga lo que significa el término plural o singular, media, es decir, es a la vez un medio masivo (mass media) y un nuevo medio". Refiere que el término mass media, "acuñado en los veinte con el advenimiento de las redes nacionales de radio y la circulación masiva de periódicos y revistas", designa a los medios que llegan a grandes públicos vía los periódicos, películas, radio, televisión y, más recientemente, la World Wide Web5 (que inició en 1993). Esta última

5 Serrano y Martínez (2003) sostienen que la www nace en 1993 y que tuvo como predecentes inmediatos al sistema de hipertexto desarrollado por Tim Bernes-Lee de la Organización Europea para la Investigación Nuclear (CERN-Conseil Européen pour la Recherche Nucleaire) en Suiza, que posibilitó navegar entre documentos por medio de hiperligas de texto e imágenes con gran éxito, el cual ahora se constata. Años después aparece el 
califica desde luego como parte de los nuevos medios, pues potencialmente lleva contenidos tanto personalizados como para un público amplio, masivo, además de ser interactiva.

Ante estas conceptualizaciones coincidimos con Nyiri (2005) en que el celular es el "nuevo medio por excelencia", pues su vocación primigenia es la interactividad de persona a persona, pero con la incorporación de capacidades para transmitir contenidos para televisión, se puede sostener que es también un mass media. La gente no sólo puede usarlo como radiotransmisor, para hablar o leer noticias cortas, mientras se desplaza de un lugar a otro, sino también para enviar textos, ver programación de televisión o Internet, tomar y enviar fotografías y entretenerse con juegos electrónicos, entre otras actividades.

Para los sociólogos tampoco llamaba la atención el estudio del teléfono de casa, por la razón, según Geser (2005), de que las conexiones que permite corresponden al nivel de la interacción bilateral, es decir, da lugar a interacciones personalizadas que se consideran de poco interés para quienes estudian procesos sociales de mayor envergadura. Esto difiere del gran interés que atrajeron los estudios sobre Internet; tecnología que también se ha expandido con rapidez y que brinda soporte a relaciones multilaterales de todo tipo: da vida a grupos virtuales, comunidades y organizaciones, así como a redes sociales a escala local, regional y global; para su acceso, por ejemplo, se ha recurrido a diferentes tipos de programas públicos (ciudades digitales) y de iniciativa privada (cibercafés) (Ruelas \& Ramírez, 2008).

Una posición intermedia sobre la prevalencia del objeto de estudio de las comunicaciones interpersonales y las comunicaciones masivas es la de Williams y Rice (1993, p. 201). A propósito de las tecnologías de comunicación emergentes, ellos discuten las mejores estrategias para su investigación y parten del hecho de que los nuevos artefactos y servicios que les dan forma, son variaciones o extensiones de los viejos medios. Entre estos incluyen el videotexto, teletexto, correo electrónico, videos

navegador gráfico comercial Mosaic ingeniado por Marc Andeersen y estudiantes programadores del National Center for Supercomputing Application localizado en la Universidad de Illinois en Urbana-Champaign. Esos desarrollos ayudaron a catapultar el uso de Internet (p. 34). 
y audioconferencia, radiodifusión por satélite, videodiscos y grabadoras en videocasetes, computadoras personales y redes de cómputo. Para ellos, los nuevos y tradicionales medios son básicamente extensiones de los sentidos y efectos humanos, y no existe entre ambos tanto grado de discontinuidad como sí lo hay entre los medios tradicionales y los naturales (oír, ver y hablar).

Debemos considerar que, en vez de separación entre las comunicaciones masivas y las interpersonales, existe un continuum de las conductas comunicativas, y que también muchos nuevos medios son interactivos y se usan en una gran variedad de situaciones, como comunicaciones interpersonales flexibles, en el acceso privado de información pública y comunicación grupal. Williams y Rice (1993, p. 201), parten del hecho de que la distinción categórica entre diferentes tipos de comunicación se ha reducido por el cambio tecnológico, y que en las comunicaciones tradicionales existe una distinción visible entre fuentes de información personalizada y la comunicación impersonal. Por ejemplo, si una persona quiere aprender más de otra o incidir en la conducta de otro, puede enfrascarse en una interacción directa, y esta suerte de instrucción o información personalizada no se puede obtener leyendo los tradicionales diarios o viendo televisión. Ahora podemos también acceder a fuentes de información personalizada en tiempo real o diferido a través de redes de computadora, por correo electrónico o teléfono celular para interactuar con otros. Además, las fuentes de satisfacción de necesidades de comunicación personal ya no están limitadas a la comunicación cara a cara, al correo postal o al teléfono tradicional.

\section{ESTUDIOS INICIALES SOBRE EL TELÉFONO CELULAR}

Los estudios sociales sobre el teléfono celular iniciaron casi a la par que su difusión masiva en 1994 y las encuestas con fines académicos proliferaron para finales de esa década. Si tomamos en cuenta que para 1998 ya se había consolidado como un medio de comunicación alternativo, además del grado de desarrollo alcanzado por las teorías y métodos de investigación de las tecnologías de información y comunicación, la reacción de la comunidad científica ante este fenómeno fue más bien cauta, pues el desarrollo de la comunicación celular, tanto de las bases 
de radio como de la tecnología de los aparatos comienzan desde finales de la década de los años cincuenta. ${ }^{6}$

El invento del aparato más parecido a los actuales se le acredita a Martin Cooper un investigador de Motorola, quien desarrolló el modelo Motorola DynaTac en abril de 1973. Tenía 3 pulgadas de largo y 5 de ancho con un espesor de 1.75 pulgadas; pesaba 2.5 libras y tenía un tablero para 30 circuitos. Su tiempo de recarga era de 10 horas pero soportaba solamente 35 minutos de estar hablando. El usuario hablaba, oía y marcaba números usando el teléfono celular, pero carecía de una pantalla como las actuales para ver sus aplicaciones. En 1977 se probó en Estados Unidos, en Nueva York y luego en Chicago; se hicieron los primeros contratos para 2,000 personas, siguiéndole Washington, DC y Baltimore. Atravesó una temporada de latencia de más de 35 años, pues

6 En 1957 hubo experimentos para desarrollar un teléfono móvil ligero, que se portara fácilmente y estuvo a cargo de Leonid Kuprivanovich en Moscú, quien logró operarlo a través de una estación de radio a una distancia de 20-30 Km. En ese año patentó el móvil aunque pesaba $3 \mathrm{~kg}$, pero al año siguiente ya tenía una versión para bolsillo de medio kilo. Otra versión de teléfono móvil que operaba automáticamente se desarrolló en Bulgaria en 1966; se coordinaba con una estación de base RATZ-10 y en 1967 se decidió que cada teléfono móvil pudiera estar en un área celular atendido por una estación durante una llamada telefónica completa. Como se pensó que se requería una estación para su operación, rompió con la continuidad del servicio automático, es decir, que pudiera moverse a través de diferentes áreas celulares. Tres años después, en 1970, Amos Joel en los Laboratorios Bell en Estados Unidos inventó un sistema que operaba automáticamente y permitía a los celulares moverse a través de muchas áreas celulares durante una llamada, sin que se interrumpiera la conversación. En 1971, ATT propuso un servicio celular que pronto aprobó la Comisión Federal de Comunicaciones (FCC-Federal Communications Commission). Otro desarrollo en la historia de los teléfonos celulares estuvo a cargo de la red ARP (adress resolution protocol) lanzada en Finlandia en 1971. Fue una de las primeras redes comerciales para teléfonos móviles en el mundo, por lo que se le conoce como la Generación Cero (0G) (http://lifestyle.iloveindia.com/lounge/history-ofcell-phones-4593.html\#). 
hasta 1979 apareció el primer sistema comercial en Japón, y en Estados Unidos en 1983. En México la compañía Iusacell empezó a ofrecer el servicio en la ciudad de México en 1989, pero es hasta finales de los años noventa cuando despegó su diseminación en el país (The origin of the cell phone). ${ }^{7}$

Para 2001, Barry Brown (2002, p. 3) reclamaba que a pesar de los vastos capitales que se invertían en la infraestructura de redes móviles y en las subastas de radiofrecuencias, ${ }^{8}$ la investigación sobre el teléfono móvil desde el punto de vista no tecnológico era reducida. Para entonces ya eran evidentes sus efectos en aspectos como la organización diaria de la agenda personal, en las rutinas de trabajo, en el cultivo de las amistades e incluso en la nueva cara que adquieren los lugares públicos al ser testigos de conversaciones privadas e íntimas.

El retraso en las investigaciones sociales del teléfono móvil se correspondió como mencionamos, con la tardanza que se tuvo para adoptar la tecnología y comercializarla con éxito. Se consideraba que trabajar en el tema era como estar perdido en el desierto o en un área académica poco respetable (Brown, 2002, p. 9). Incluso dentro de los Laboratorios Bell de ATT, donde se llevaba a cabo la mayor parte del trabajo sobre las comunicaciones celulares, la situación era similar, pues antes de la década de los años ochenta la investigación era una pequeñísima parte de la que desarrollaban los científicos e ingenieros en esos laboratorios y se concebía como una actividad profesional de bajo perfil (Brown, 2002). Ahora se reconoce como una de las grandes fallas de cálculo de los ejecutivos de la transnacional, haber atendido la estimación de la consultoría McKinsey de que para inicios del siglo el mercado mundial de telefonía celular sería de 900,000 usuarios por la baja calidad de los aparatos y los costos de las llamadas, siendo que el mercado llegó a tener para entonces un crecimiento de 900,000 clientes cada tres días (The Economist, 1999).

Desde 1994 cuando la adopción de la telefonía celular inició de manera sostenida, su análisis también empezó a capturar la atención de

7 Recuperado el 5 de agosto de 2009 de http://www.articlesbase.com/cellphones-articles/the-origin-of-the-cell-phone-63578.html\#

8 En la subasta por las radiofrecuencias para la tercera generación de celular, en Gran Bretaña se pagaron 22 billones de euros (Brown, 2002, p. 3). 
diversas disciplinas, de académicos universitarios y de las empresas del sector; los diarios daban cuenta cotidiana de múltiples vicisitudes que surgían alrededor de este medio de comunicación. Los esfuerzos más tempranos se dieron en una encuesta realizada en 1995, considerada por su autor como la primera en el nivel nacional aplicada para comparar usuarios y no usuarios del celular en Estados Unidos (Katz, 2005, p. 171) y para conocer las consecuencias sociales de su adopción (Katz, 1999).

En la primera década del nuevo siglo, el teléfono celular ha adquirido ya una importancia primaria para la sociedad y los individuos. Pertenece, indudablemente al conjunto de artefactos que se han mundanizado o popularizado: la cultura es cada vez más influenciada por el incremento de estas sofisticadas tecnologías de comunicación e información que incrementan las capacidades personales. Incluso la tecnología inalámbrica que constituye su soporte se utiliza en aplicaciones para servicios de rescate, para monitorear instalaciones costosas en lugares aislados, pero también para máquinas automáticas expendedoras de líquidos, golosinas, entre otras.

El análisis del teléfono móvil aunque novedoso por lo reciente de su adopción, adquiere un inusitado entusiasmo, equiparable a su galopante aceptación mundial. Según Cooper (2002, p. 21), la proliferación de investigaciones sobre el móvil se relaciona con la convergencia y la inminencia de su cambio de estatus, pues se cataloga como un punto de acceso para adquirir información bajo un formato novedoso que ha dado a la tecnología mayor visibilidad: el hecho de que gran cantidad de usuarios -sean adultos, jóvenes y niños, de bajos o altos ingresosporten un aparato, le da una visibilidad inconmensurable frente a la que dan otros artefactos portátiles, incluso que el reloj de pulso, las alhajas o el bolso que utilizan universalmente las mujeres. Aunque en última instancia son las personas y sus hábitos al usarlo, los que moldean y orientan los nuevos desarrollos de esta tecnología.

\section{VISIONES DISTÓPICAS}

La proliferación de artefactos móviles y la noción del teléfono móvil como una tecnología ubicua redimensionan problemas de investigación enunciados por la irrupción de diversas aplicaciones de tecnologías de 
información y comunicación desde finales del siglo XX. En este artículo englobamos como visiones distópicas a los debates sobre las primeras reacciones adversas que ha provocado la inmensa diseminación y la portabilidad del teléfono celular. Las perspectivas distópicas tienden a ver a las nuevas tecnologías como una amenaza social, es decir, un conjunto de temores sobre el bienestar de los usuarios, particularmente los niños, los escenarios mundiales catastrofistas, la acechanza de peligros, horrores médicos y amenazas a la decencia o la moral, que frecuentemente surgen por la emergencia y adopción de tecnologías para el uso cotidiano. ${ }^{9}$ Esto ocurre especialmente, según May y Hearn (2005, p. 195) cuando tecnologías emergentes remueven creencias populares acendradas. Ahora están a la orden del día avisos sobre posibles catástrofes asociadas con el uso del teléfono celular: el cáncer de cerebro para usuarios asiduos, incendios en estaciones de gasolina, accidentes de tránsito, deformaciones de los órganos por la exposición a las antenas receptoras de señales, uso para cometer fechorías o como modus operandi de bandas delincuenciales por ser un instrumento insuperable para la extorsión y el secuestro.

Otras tecnologías que llamaron la atención por considerar ciertos efectos de ellas como nefastos y amenazantes para la vida y conductas humanas son: los videos, las bases de datos, la biotecnología, la televisión y las aplicaciones nucleares. También contribuyen a los escenarios utópico-distópico la proliferación de la mensajería instantánea, el chat, páginas de Internet para adultos, juegos en línea, la intimidación cibernética, engaños en exámenes escolares e imágenes comprometedoras tomadas desde móviles.

El advenimiento de la economía digital da pauta para que se acentúen los sentimientos de miedo o vulnerabilidad. Vivimos cambios de largo alcance, pues de una forma de producción industrial pasamos a una do-

9 Según Claude Fischer (1991), desde 1889 el British Medical Journal, apuntaba que a medida que la civilización avanza se producen nuevas clases de enfermedades, ya sea del cuerpo o de la mente. Cuando se introdujo el teléfono surgieron temores de irrupción de enfermedades. Incluso las mentes y cuerpos fuertes se consideraron susceptibles por el "casi constante agobio del aparato auditivo" en las personas que lo usaban muy frecuentemente. 
minada por productos culturales, donde cada vez el comercio de frontera involucra mercancías culturales que llegan a explotar bienes intangibles como los sentimientos, la moda, el bienestar, los gustos por la cocina, la diversión, el entretenimiento electrónico y los juegos virtuales. Según May y Hearn (2005) "cuando la economía se digitaliza y alcanza los asuntos íntimos de la vida personal, se puede esperar que muchas cosas importantes ocurran" (p. 199). El ejemplo más común de temores alrededor de nuevas mercancías culturales y por lo extendido del mercado de juegos electrónicos y en línea, son los miedos crecientes de los padres por la exposición digital de niños y adolescentes a agentes extraños.

Un aspecto que encaja en las posiciones distópicas de los medios de comunicación proviene del rasgo comunicativo copresente que se concreta en las llamadas por celular. Es decir, cuando alguien al hablar desde cierto lugar, se pone en una situación de ausencia-presencia simultáneamente y arriesga la seguridad personal mientras se camina o conduce un automóvil. Al hablar por celular, aunque se esté físicamente presente en un sitio, la orientación mental o atención se centra en alguien ausente, a lo que Rich Ling (2004) llama "desconectarse mentalmente" del lugar donde uno se encuentra para tener que contestar el teléfono, siendo éste "el punto más difícil de un episodio telefónico", lo cual puede tornarse riesgoso por perderse el sentido del lugar, particularmente cuando se atraviesa una calle muy transitada o al manejar un automóvil. De acuerdo con Katz, Aarhus, Kim y Turner (2003) esto no es un fenómeno transitorio, pues se ha demostrado que los conductores que usan el teléfono al manejar están mentalmente ausentes o absortos en una conversación, lo que provoca gran cantidad de accidentes de tránsito, y por ello cada vez más gobiernos locales prohiben, como se hizo inicialmente en Alemania, utilizar el celular mientras se maneja, obligando a usar diademas, al menos para no tener ocupada una mano al sostener el aparato.

Los celulares son a menudo criticados porque se cree distorsionan una auténtica interacción cara a cara, concebida así por los defensores de la comunicación interpersonal pura. Reid y Reid (2005, p. 106) sostienen que, por ejemplo, los mensajes de texto son un distractor del contacto personal íntimo y dan pauta para no involucrarse personalmente y deshacerse del manejo de la autopresentación. 
La particularidad de ser un medio móvil, accesible en espacios abiertos o cerrados, puede provocar que al usarse se ignore no sólo el aquí y ahora, sino a los otros, lo que se interpreta como una falta de urbanidad y provoca un conflicto situacional. El principal problema de hablar por celular frente a otro, es la muestra de descortesía ante la persona presente (Dunbar, 2002) pues a la vez que se le ignora, se interrumpe una conversación cara a cara, o el diálogo abierto en un espacio público. Es decir, los espacios sociales se traslapan como consecuencia del uso del móvil y ocurre lo vislumbrado por el filósofo búlgaro $\mathrm{K}$. Nyiri (2005): que ya no sea una violación a las normas de urbanidad.

También aplica lo señalado por Howard T. Hall (citado en Hoflich, 2005) y que aparece como más perturbador: la falta de orientación en el espacio mientras se habla por el celular trae como consecuencia manifestaciones "psicóticas", es decir, personas que "hablan solas" al deambular o esperar en un lugar público, gesticulando como si estuvieran frente a un interlocutor. Pero también ya ocurre que nos hemos acostumbrado a ver como normales estas manifestaciones sin que siquiera llamen la atención.

Otras opiniones que se pueden agrupar en las visiones distópicas giran en el sentido de que el uso del celular mercantiliza los espacios geográficos por el hecho de que se consume tiempo abierto o público a costa de espacios comunes, culturales y psicológicos.

Cuando se camina por la calle y se va hablando por el celular, no estás en la calle compartiendo una experiencia comunitaria de la vida urbana... lo que importa porque la calle es el último espacio público, y caminar sobre ella es lo que define la experiencia urbana (Goldberger, 2003).

Aunque esto contrasta con la opinión de Kofomaa (2000) que sostiene que el móvil "le agrega vitalidad al espacio público".

Así mismo, la inmensa mercantilización de los teléfonos, particularmente los de la última generación tecnológica, que combinan videos, Internet y textos a través de banda ancha digital (Flew, citado en May y Hearn, 2005), no sólo son un rasgo de estatus social, sino que su consumo forma parte de la identidad y la autoconstrucción de las personas (Poster, 2004). 


\section{EL TELÉFONO MÓVIL, MEDIO SUBVERSIVO \\ Y REGRESIVO DE LAS RELACIONES SOCIALES}

La inconmensurable diseminación de las tecnologías de información ha dado pauta para que se reafirmen -como es el caso del celular-y se conviertan en mecanismos para subvertir el orden establecido, es decir, tecnologías que a veces llevan a cambios inesperados (Sawhney, 2005), o bien que contribuyen a disolver la sociedad civil (Nyiri, 2003). Para Sawhney (2005, p. 45) las tecnologías de comunicación tienen un enorme potencial subversivo, ya que pueden poner en peligro el orden establecido, pues la comunicación es un tipo de interacción que activamente busca la variedad. 10 Según Marvin (1988), no importa qué tan firme, afianzado u organizado esté un orden, las tecnologías de comunicación llevan consigo la semilla de la subversión. Tenemos, por ejemplo, el hecho de que el presidente de Filipinas José Estrada tuvo que dimitir al cargo en enero de 2001 a raíz de las protestas de la gente, facilitadas a través de millones de mensajes por celular. Según Reinghold (2002, p. 160), en 75 minutos se logró reunir a más de 20,000 personas en una especie de asamblea "antiestrada" en Manila. Éste se ha convertido en el ejemplo típico del uso que se les puede dar a las nuevas tecnologías de comunicación como el celular o las redes sociales en línea, para concitar o convocar a grupos sociales para tomar acciones políticas.

Diversos estudios sobre las funciones o posibilidades de las comunicaciones por celular muestran posiciones contradictorias sobre el papel del teléfono como medio para la organización. Según el sociólogo Hans Geser (2005), por una parte, se le ve como medio para la organización, al posibilitar la integración de organizaciones complejas y de millones de procesos de coordinación dentro de las ciudades que no pudieran realizarse en la interacción cara a cara, pues si no lo tuviéramos, la gente tendría que mover mensajeros la mayor parte del tiempo (Lasen, 2005). Pero, por el contrario, también puede considerársele como el medio de la des-

10 Sawhney (2005, pp. 45-61) discute si el despliegue de la tecnología Wi-Fi, dará al traste con la configuración prevaleciente de las redes de telecomunicaciones, y a partir de ello le otorga un carácter subversivo a la tecnología inalámbrica que integra una infraestructura en red. 
organización pues provoca anarquía al permitir potencialmente que todos estemos al alcance de todos en cualquier dirección y momento, haciendo a un lado los canales formales de comunicación (Bahrdt, citado en Geser, 2005). Esto trae efectos disruptivos especialmente pronunciados en organizaciones burocráticas donde los flujos de comunicación son verticales.

Mientras que el teléfono fijo, como aparato estacionario da soporte a instituciones supraindividuales al conectar oficinas locales fijas y forza a las personas a estar en cierto lugar y usar intermediarios institucionalizados para comunicarse mutuamente (Geser, 2005, p. 24), el teléfono celular ejerce un impacto regresivo y subversivo en el sentido de que posibilita a las redes microsociales informales comunicarse eficientemente, más allá de controles institucionales. Pero, de la misma manera, los medios masivos de comunicación, la prensa escrita, la radio y la televisión, que conectan a "uno con muchos", otorgan poder a organizaciones centralizadas y formalizadas, al transmitir propaganda, comerciales y otros mensajes de empresas, gobiernos, partidos políticos y otras entidades colectivas que tienen intereses bien definidos y que van dirigidos a los individuos. Las nuevas tecnologías de información y comunicación, dice Cabrera (2006), "provocan profundos cambios en la organización y administración del poder. Son instrumentos de control y vigilancia por un lado, y herramientas de organización contestataria, por el otro" (p. 101).

Las actuales tecnologías digitales han traído una variedad de innovaciones con capacidad para hacer lenta o detener esta tendencia de dominio de largo alcance de organizaciones y sistemas establecidos (Geser, 2005). Al utilizar Internet los individuos tienen oportunidad de involucrarse en todo tipo de interacciones bilaterales o multilaterales para buscar información o publicar puntos de vista personales a escala mundial. Por su parte, con el teléfono móvil se ensancha la esfera de interacción microsocial, pues los individuos tienen teóricamente las condiciones para alcanzar a otros sin necesidad de sujetarse a normas institucionales que demandan la presencia en un lugar específico (y una relación con otros en la misma locación).

Otro potencial efecto subversivo del teléfono móvil en los centros de trabajo es que brinda la posibilidad de monitorear las actividades que desarrollan los empleados fuera de las oficinas, pues se puede saber dónde se encuentran y qué hacen con cierta precisión. Estos trabajadores móviles 
enfrentan dos realidades: la necesidad de armonizar actividades programadas y monitoreadas, y combinarlas con imprevistos. Además, sufren la tensión de estar disponibles para sus jefes a cualquier hora y en cualquier lugar por la ubicuidad del teléfono celular. La conectividad a la que están expuestos les puede producir tensiones y sobresaltos, pues es factible que se les ubique en los sitios precisos. El hecho de que reciban mensajes de voz o de texto de sus jefes, y no los atiendan, puede implicar que han fallado en el cumplimiento del trabajo por el simple hecho de ignorar una orden o petición dejada en el buzón. Es decir, hoy el tiempo-espacio o disponibilidad de las personas se extiende, más allá de un horario hábil. Con el identificador de llamadas se posibilita tener sobre los trabajadores un marcaje fino en cuanto a sus actividades (Lasen, 2005, p. 38).

Pero también el teléfono juega una función importante en la organización de las actividades y las relaciones entre los miembros del hogar. Por un lado, brinda tranquilidad por la posibilidad de saber en cualquier momento dónde y cómo están los hijos, pero por otro, la accesibilidad se vuelve una herramienta de vigilancia o monitoreo de los padres hacia sus hijos menores, quienes se resisten al estar en una etapa donde buscan manejar sus propios asuntos y volverse independientes (Ling, 2004). Es decir, el teléfono celular trabaja como una especie de "aparato antievolución" al facilitar la "vuelta a lo más simple, a patrones premodernos de la vida social" (Geser, 2005, pp. 24-25) por el control que se puede volver a tener sobre los adolescentes.

Para Geser (2005), el teléfono móvil potencia el socavamiento, en cuatro diferentes formas, de las tendencias de desarrollo social de largo plazo, al menos desde el inicio de la revolución industrial y por el aumento de grandes organizaciones burocráticas. Esto, según el mismo autor, pone en duda las teorías macrosociales sobre el desarrollo de las sociedades modernas:

1. Incrementa los lazos sociales primarios.

2. Reduce la necesidad de coordinación basada en horarios preestablecidos.

3. Potencia el socavamiento de los controles institucionales y el reemplazo de los sistemas de comunicación basados en el lugar, por los sistemas de comunicación personales.

4. Ayuda a mantener roles anacrónicos dominantes. 


\section{INCREMENTA LOS LAZOS SOCIALES PRIMARIOS}

La primer forma como el teléfono móvil puede socavar la tendencia del desarrollo social tiene que ver con que esta manera de comunicación tiende a cerrar más el círculo de relaciones familiares y de amigos cercanos, es decir, incrementa los lazos sociales ya existentes, más que abrir nuevos. Esto se ha mostrado con estudios empíricos como el realizado en Finlandia (Kasesniemi \& Rautiainen, 2002), donde resultó que los usuarios se comunicaban primordialmente con dos o tres miembros del hogar. Lo mismo en Italia, donde se reporta que el uso más fuerte es para estar en contacto con los más allegados (Fortunati, 2003, p. 56). Así mismo, se ha demostrado que los coreanos estrechan los lazos sociales existentes más que abrir nuevos y en los japoneses se ha encontrado que una de las funciones más importantes de Internet por celular es para entrar en contacto con amigos cercanos (Miyaki, 2005).

La mayor relevancia del "efecto regresivo" del uso del celular se ilustra con los resultados de un estudio europeo de 1999 donde casi $85 \%$ de los usuarios jóvenes entre 14 y 24 años opinaron que el teléfono móvil ayuda a estar en contacto continuo con amigos y familiares (Ling, 2004, p. 60). Igualmente Fox (citado en Geser, 2001, p. 26) describe cómo el teléfono celular funciona como una herramienta poderosa para reestablecer la vida comunal tradicional mediante la comunicación informal, casual o típica. De esa manera se contrarresta la pérdida de integración social comunal causada por los medios masivos tradicionales, así como la despersonalización de la vida urbana moderna.

\section{REDUCE LA NECESIDAD DE LA COORDINACIÓN BASADA EN HORARIOS ESTABLECIDOS}

La segunda forma en como el teléfono móvil revierte tendencias sociales es que reduce la necesidad de planeación temporal en virtud de que se puede volver a acordar un horario en cualquier momento, incluso en el último minuto. Por ello, con él emerge una nueva cultura de la interacción social informal más fluida, una coordinación ad hoc atendiendo a cambios de corto plazo, a circunstancias, oportunidades o preferencias subjetivas (Ling \& Yttri, 2002; Ling, 2004, p. 64). A ello se asocia, 
por ejemplo, que en Italia los teléfonos celulares hayan superado más pronto el número de líneas fijas, pues los italianos son espontáneos y su estilo de vida es más bien desorganizado (Fortunati, 2003, p. 55).

Los estudios empíricos muestran que la coordinación de actividades cotidiana es una de las contribuciones más notorias del celular. Ling (2004, p. 77) la cataloga como la más grande consecuencia social de la telefonía celular.

\section{POTENCIA EL SOCAVAMIENTO DE LOS CONTROLES}

INSTITUCIONALES Y EL REEMPLAZO

DE LOS SISTEMAS DE COMUNICACIÓN BASADOS EN EL LUGAR

Este es un efecto disruptivo muy particular del teléfono móvil. A diferencia del teléfono fijo que contribuyó a la estabilización del orden social basado en la localización - pues crea conexiones entre sistemas estacionarios y supraindividuales (por ejemplo oficinas u hogares) más que entre individuos- el teléfono celular ayuda a socavar los órdenes tradicionales al crear líneas directas entre particulares, independientemente de su rol institucional y ubicación. Al posibilitar la comunicación libre de intermediarios, debilita el control de las instituciones formales sobre las conductas de sus miembros. Por ejemplo, durante las horas de oficina, clases en la escuela, obligaciones militares, cuando se conduce el automóvil o pilotea un avión. Las escuelas no saben si prohibir el uso del celular, pues los padres de los estudiantes desean estar en contacto con sus hijos a toda hora. Por ello, los controles centralizados que han ejercido las instituciones son difíciles de mantener, y sus fronteras espaciales y temporales se vuelven más simbólicas o maleables.

\section{AYUDA A MANTENER ROLES ANACRÓNICOS O DOMINANTES}

Otro de los efectos disruptivos de la telefonía móvil es que contribuye a mantener roles dominantes que la vida moderna tiende a transformar. El hecho que una mujer potencialmente esté disponible en todo momento, incluso cuando se encuentra enfrascada en una actividad no doméstica, lleva a la preservación de sus roles históricos. Con el celular, las madres, siguen estando atadas a sus hijos todo el día aunque estén traba- 
jando o viajando. Se facilita la perpetuación (más que eliminación) de la tradicional división del trabajo de género, pues las madres tienen que seguir al pendiente de sus hijos aunque estén trabajando (Ling, 2004, p. 63), y así los esposos de "madres remotas" (Rakow \& Navarro, 1993) exitosas pueden evadir sus obligaciones familiares.

Los médicos también corren esta suerte, pues pueden estar disponibles al margen de un horario o cuando se les necesite; a los propietarios de negocios igualmente les ayuda a preservar su tradicional liderazgo patriarcal, y así se inhiben procesos diferentes de organización (Geser, 2005, p. 30) o la delegación de responsabilidad a sus subordinados. En suma, los celulares dan nuevo ímpetu a la vieja idea de que los individuos pertenecen exclusivamente a un grupo, comunidad $\mathrm{u}$ organización en particular, a los que se deben incondicionalmente y sin límite de tiempo. Esto da al traste con los recientes desarrollos sociales sobre la autonomía individual: a la capacidad de las personas de mantener una esfera privada, así como a dividir sus compromisos en diferentes roles segregados (p. 30).

\section{CONCLUSIONES}

Frente al fenómeno social en que se ha convertido el teléfono celular tenemos la oportunidad de estudiar una nueva tecnología de comunicación, sus periodos de ajuste y fricciones que acompañan su adopción inicial. Aprovechemos, como dice Marvin (1988, p. 8), la tensión que crea la coexistencia de lo viejo con lo nuevo, y también aprovechemos la existencia de antecedentes de prácticas sociales alrededor del teléfono fijo que nos sirvan de contraste con las nuevas manifestaciones culturales del teléfono celular. Las conductas de ubicuidad que ha inducido, la riqueza de folclore que lo rodea por su portabilidad (listo para traerse) y lo rápido de su desarrollo reta a los estudiosos de las comunicaciones, la cultura, la economía política y otras disciplinas a ocuparse de este fenómeno social. Esperemos que no nos gane el hecho de que al ser un artefacto de la rutina, de la vida cotidiana, sujeto a rápidos cambios, se oscurezca pronto para la ciencia.

Es claro que los estudios iniciales sobre el teléfono celular deben verse en el contexto de su despegue a principios de la década del nuevo milenio. Los estudios que aquí hemos referido se realizaron cuando aún 
los celulares no rebasaban al número de teléfonos fijos, cuando su uso en público, por ejemplo, retaba las normas de etiqueta y los buenos modales. Hoy eso ha cambiado.

Actualmente el teléfono móvil concita otras preocupaciones analíticas relacionadas con su convergencia tecnológica con aplicaciones para Internet, para videograbación, como localizador geográfico, como auxiliar en los procesos de enseñanza aprendizaje y en el mapeo de catástrofes naturales. Pero también hay problemáticas sociales que siguen presentes, tal como su apasionada adopción por adolescentes y niños y sus efectos en las relaciones y los roles familiares. En México, en un contexto de pobreza persistente y creciente, se impone estudiarlo desde la perspectiva de la división digital para conocer si su amplia diseminación, bajo los cánones mercantilistas, oscurece las obligaciones públicas en materia de telecomunicaciones.

Es importante que sigamos estudiando estos nuevos fenómenos sociales con perspectivas multidisciplinarias y con métodos etnográficos en grupos poblacionales y en latitudes geográficas demarcadas. Ello nos podrá ayudar a discernir si el extensivo uso del celular está dando lugar sólo a nuevas manifestaciones o si actúa como mecanismo que replica manifestaciones sociales preexistentes.

\section{Bibliografía}

Brown, B. (2002). Studying the use of mobile technology. En B. Brown, N. Green \& R. Harper (Eds.), Wireless world. Social and interactional aspects of the mobile age (pp. 3-15). Londres: Springer-Verlag.

Cabrera, D. H. (2006). Movimiento y conexión. Política y Sociedad, 2, (46), 91-105.

Cooper, G. (2002). The mutable mobile: social theory in the wireless world. En B. Brown, N. Green \& R. Harper (Eds.), Wireless world. Social and interactional aspects of the mobile age (pp. 19-31). Londres: Springer-Verlag.

Cutting the cord. (1999, 9 de octubre). The Economist, pp. 6-12.

De Sola Pool, I. (Ed.). (1977). The social impact of the telephone. Cambridge: MIT Press.

Dimmick, J. W., Skiand, J. \& Patterson, S. J. (1994, octubre). The gratifications of the household telephone. Sociability, instrumentality, and reassurance. Communication Research, 21 (5), 643-663. 
Dunbar, R. (2002). Grooming, Gossip, and the Evolution of Language. Cambridge, MA.: Harvard University Press.

Fischer, C. (1991). America calling: a social history of the telephone to 1940. Berkeley: University of California Press.

Fortunati, L. (2003). The mobile phone and democracy: an ambivalent relationship. En K. Nyíri, Mobile democracy (pp. 239-258). Essays on society, self and politics. Viena: Passagen Verlag.

García, L. (2008). Las ciencias de la comunicación a la luz de las nuevas tecnologías: retos para una disciplina en la incertidumbre. Global Media Journal-Edición Iberoamericana, (5)10. Recuperado el 31 de enero de 2010 de http://gmje.mty.itesm.mx/lascienciasdelacomunicacion.pdf

Geser, H. (2005). Is the cell phone undermining the social order? Understanding mobile technology from a sociological perspective. En P. Glotz, S. Bertschi \& C. Locke (Eds.), Thumb culture. The meaning of mobile phones for society (pp. 23-35). Bielefeld: Verlag.

Goldberger, P. (2003). Disconnected urbanism. The cell phone has changed our sense of place more than faxes, computers, and e-mail. Metropolis. Recuperado el 29 de octubre de 2008 de http//:www. metropolismag.com/story/20070222/disconnected-urbanism

Hoflich, J. R. (2005). The mobile phone and the dynamic between private and public communication: Results of an international exploratory study. En P. Glotz, S. Bertschi \& C. Locke (Eds.), Thumb culture. The meaning of mobile phones for society (pp. 123-135). Bielefeld: Verlag.

Ibarra López, A. M. (1995). Apuntes para una historia de la telecomunicación en México. Revista Comunicación y Sociedad, 22-23, septiembre 1994-abril 1995, 103-146.

Kasesniemi, E. \& Rautianen, P. (2002). Mobile culture of children and teenagers in Finland. En J. E. Katz \& Aakhus, M. (Eds.), Perpetual contact. Mobile communication, private talk, public performance (pp. 170-192). Cambridge: Cambridge University Press.

Katz, J. E. (1999). Connections. Social and cultural studies of the telephone in American Life. New Brunswick, NJ.: Transaction Publishers.

Katz, J. E. (2005). Mobile communication and the transformation of daily life: The next phase of research on mobiles. En P. Glotz, S. 
Bertschi \& C. Locke (Eds.), Thumb culture. The meaning of mobile phones for society (pp. 171-182). Bielefeld: Verlag.

Katz, J. E., Aarhus, M., Kim, H. D. \& Turner, M. (2003). Cross-cultural comparisons of ICTs. En L. Fortunati, J. E. Katz \& R. Riccini, (Eds.), Mediating the human body. Technology, communication, and fashion (pp. 75-86). Nueva Jersey; Londres: Lawrence Erlbaum Associates.

Kopomma, T. (2000). The city in your pocket. Birth of the mobile information society. Helsinki: Gaudeamus.

Lasen, A. (2005). History repeating? A comparison of the launch and uses of fixed and mobile phones. En L. Hamill \& A. Lasen (Eds.), Mobile world. Past, present and future, (pp. 929-960). Netherlands: Springer.

Ling, R. \& Yttri, B. (2002). Hyper-coordination via mobile phones in Norway. En J.E. Katz \& M. Aakhus (Eds.), Perpetual contact. Mobile communication, private talk, public performance (pp. 139169). Cambridge: Cambridge University Press.

Ling, R. (2003). Fashion and vulgarity in the adoption of the mobile telephe among teens in norway. En L. Fortunati, J. E. Katz \& R. Riccini (Eds.), Mediating the human body. Technology, communication, and fashion (pp. 93-102). Nueva Jersey; Londres: Lawrence Erlbaum Associates.

Ling, R. (2004). The mobile conection. The cell phone's impact on society. Amsterdan: Morgan Kaufmann.

Marvin, C. (1988). When old technology were new. Thinking about electric communication in late nineteenth century. Nueva York: Oxford University Press.

May, H. \& Hearn, G. (2005). The mobile phone as media. International Journal of Cultural Studies, 8, (195),195-211.

Miyaki, Y. (2005). Keitai use among Japanese elementary and junior high school students. En M. Ito, D. Okabe \& M. Matsuda (Eds.), Personal, portable, pedestrian. Mobile phones in Japanese life (pp. 277-299). Cambridge; Londres: The MIT Press.

Nyiri, K. (Ed.). (2003). Mobile democracy. Viena: Passengen Verlag.

Nyiri, K. (2005, 28-30 de abril). The mobile phone in 2005: where are we now? Conferencia presentada en el congreso internacional Communications in the $21^{\text {st }}$ century. The mobile information socie- 
ty "Seeing, understanding, learning in the mobile age". Budapest: Hungarian Academy of Sciences/T-Mobile.

Palau, M. (2008). La transdisciplinariedad en los estudios de medios de comunicación en Mexico. Global Media Journal -Edicion Iberoamericana, 5 (10). Recuperado el 30 de enero de 2010 de http:// gmje.mty.itesm.mx/latransdisciplinariedad.pdf

Poster, M. (2004). Consumption and digital commodities in the everyday. Cultural Studies, 18 (2-3), 409-423.

Rakow, L. F. \& Navarro, V. (1993). Remote mothering and the parallel shift: women meet the cellular telephone. Critical Studies in Mass Communication, 10, 144-157.

Reid, D. J. \& Reid, F. J.M. (2005). Textmates and text circles: insights into the social ecology of SMS text messaging. En L. Hamill \& A. Lasen (Eds.), Mobile world. Past, present and future (pp. 105-118). Netherlands: Springer.

Reinghold, H. (2002). Smart Mobs. The next social revolution. Cambridge, MA.: Perseus Publishing.

Reardon, K. \& Rogers, E. M. (1988). Interpersonal versus mass media communication. A false dichotomy. Human communication research, 5 (2), Invierno. 284-303.

Rogers, E. (1986). Communication technology: the new media in society. Nueva York: Free Press.

Ruelas, A. L. \& Ramírez, A. E. (2008, septiembre). Internet y cibercafés en Culiacán. Enfoques y realidades. Revista Razón y Palabra, 64. Recuperado el 30 de enero de 2010 de http://www.razonypalabra.org.mx/N/n64/varia/ruelas_ramirez.html

Ruelas, A. L. (2010). El teléfono celular y los jóvenes sinaloenses. Adopción, usos y adaptaciones. Borrador para publicación.

Sarch, A. (1993). Making the connection: single women's use of the telephone in dating relationships with men. Journal of Communication, 43 (2), 28-144.

Sawney, H. (2005). Wi-fi networks and the reorganization of wirelinewireless relationship. En R. Ling \& P. E. Pedersen (Eds.), Mobile communications. Renegotiation of the social sphere (pp. 45-61). Londres: Springer. 
Serrano Santoyo, A. \& Martínez Martínez, E. (2003). La brecha digital. Mitos y realidades. México: UABC.

Williams, F., \& Rice, R. E. (1993). Communication research and the new media technologies. En R. N. Bostron, y B. H. Westley (Eds.), Communication Yearbook, 7, 200-224. Beverly Hills: Sage.

\section{Recursos en Internet}

The origin of the cell phone. Recuperado el 5 de agosto de 2009 de http://www.articlesbase.com/cell-phones-articles/the-origin-of-thecell-phone-63578.html\#

History of cell phones. Recuperado el 12 de septiembre de 2009 de http://lifestyle.iloveindia.com/lounge/history-of-cell-phones-4593. html\# 